\title{
Mars the sublime
}

\section{The first images from the Mars Express orbiter highlight the universal beauty of the wilderness.}

\section{Martin Kemp}

"It's just so beautiful as well as awe-inspiring... It's art and science and beauty and exploration all mixed up together". John Murray of Britain's Open University, one of the international team involved in the European Space Agency's current mission to Mars, is speaking about the first images to be produced by the High Resolution Stereo Camera (HRSC) on the agency's Mars Express orbiter. Looking at this view of the Grand Canyon of Mars (Valles Marineris), it is easy to see why.

But why should we find beauty in the barren topography of a planet that is so hostile to life? The answer lies in the interplay of our conditioned response to particular kinds of sublime landscape and the aims behind the image's generation. Our appreciation for painted landscapes that are awesomely terrible, rather than pastorally comforting, was the product of the Romantic imagination in the eighteenth century. Edmund Burke's Philosophical Enquiry into the Origin of our Ideas of the Sublime and Beautiful in 1757 set the tone.

Wilderness, particularly the vast tracts of newly explored territories in North America, became a source of aesthetic pleasure. James Fenimore Cooper's book The Last of the Mohicans, from 1826 , plays out its tragic narrative against great vistas of mighty mountains, high plateaux and deep valleys. Our primitive and fundamental emotions seem to be more naturally expressed in savage topographies than in the artificial enclosures of cities.

The rhetoric of the sublime has long been integral to the imagery of the planets. Mars Express now presents us with images of the martian surface that are analogous to the aerial views on postcards that we might buy on a visit to the Grand Canyon. But the new pictures are not simply the high-tech equivalent of high-quality snapshots. We are witness to a superbly contrived visual model, the realism of which arises from the complex synthesis of the various data collected by the HRSC.

The data are the product of a 'linescan' camera that exploits the highest levels of optical and digital

Modern man has created an indoor society, efficiently buffering environmental changes and, at the same time, choosing sustained dimness. Outside light intensities range between 10,000 and 100,000 lux (depending on cloud cover), whereas inside light rarely offers more that 100-400 lux. So the strength of the zeitgeber light, which is so important in synchronizing our biological clock, has decreased enormously as a result of industrialization. Humans have successfully conquered every available biotope, and the independence from sunlight now

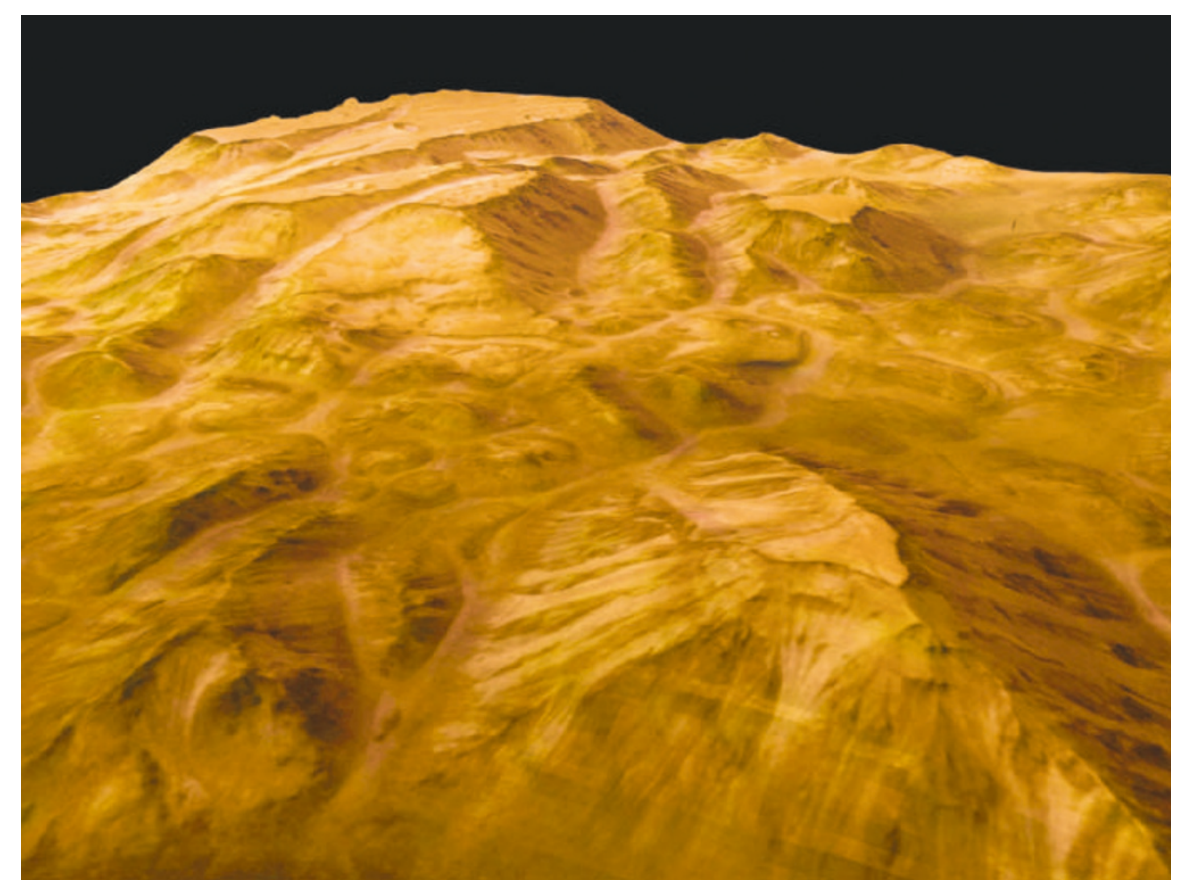

This image of Valles Marineris from Mars Express shows that barren landscapes can be beautiful too.

sophistication. It works with nine independent image strips, each of which consists of 5,184 light-sensitive cells, orientated perpendicularly to the flight direction. Three of the channels register red, green and blue, and another is sensitive in the near-infrared range. Three strips record photometric measurements, and two are dedicated to stereo information, to bring about the complete three-dimensional modelling of the planet's surface in full relief. Additionally, the data are read out at variable frequencies to accommodate the ground velocity of the orbiter.

The HRSC's resolution of up to 10 metres per pixel from an altitude of about $260 \mathrm{~km}$, the closest that Mars Express gets to the martian surface, is supplemented by a Super Resolution Channel, which produces more detailed pictures, of up to 2.3 metres per pixel. The former produces reference locations for the latter, just as we need maps of varied scales when we move from crosscountry roads into the dense grids of cities. The

allows us to conquer every temporal niche of day and night.

We experience the consequences, for example during shift work or jetlag. Over millions of years, our biological clock has learnt to interpret that we experience the brightest light during the day, independent of when we are active. But the biological clocks of shift workers (some $20 \%$ of the working population in the West) compare the dim light during the night shift with the bright light of day, and refuse to be fooled. As a result, shift workers and travellers issue of resolution is crucial to the geological analyses that are the central goal of the explorations of Mars. Whatever detailed data might emerge from the Mars landers, fundamental judgements must be made on the basis of the gross topographies of the martian mountains and valleys seen in such images.

One attraction of the sublime landscapes that were painted around 1800 was that the grand topographies bore witness to the vast and ancient processes that shaped our planet. The geology of Charles Lyell and the visions of artists spoke the same language of huge transformation. When we look at the latest pictures of the dramatically scarred surface of the red planet, we bring to them the baggage of our aesthetic predispositions, to which scientists and non-scientists alike are powerfully subject.

Martin Kemp is professor of the history of art at the University of Oxford and co-director of Wallace Kemp/Artakt.

across time zones eat (and work) when they are tired and sleep when they are hungry.

We know that our industrialized lifestyle has many consequences. Living against our biological clock and shielding ourselves from daylight may be among the most important. It is time that the profound knowledge of clock research reaches everyone in our society. This book does an excellent job in this campaign.

Till Roenneberg is at the Institut für Medizinische Psychologie, Ludwig-Maximilians-Universität, Goethestrasse 31, Munich D-80336, Germany. 